\title{
Determination of Sulphates in Model Stones and Stones from Corvins' Castle ${ }^{+}$
}

\author{
Sorina Florentina Vasile 1, George-Ionuț Radu 1, Ana-Alexandra Sorescu 1,2,*, \\ Mircea Ioan Filipescu ${ }^{1}$ and Rodica-Mariana Ion ${ }^{1,2}$ \\ 1 National Institute for Research \& Development in Chemistry and Petrochemistry -ICECHIM Bucharest, \\ 202 Spl. Independentei, 060021 Bucharest, Romania; sorina.vasile14@yahoo.com (S.F.V.); \\ radugeorgeionut@yahoo.com (G.-I.R.); mfilipescu3@gmail.com (M.I.F.); \\ rodica_ion2000@yahoo.co.uk (R.M.I.) \\ 2 Valahia University, Materials Engineering Department, 130004 Târgoviște, Romania \\ * Correspondence: ana-alexandra.sorescu@icechim.ro \\ + Presented at the 15th International Symposium "Priorities of Chemistry for a Sustainable Development" \\ PRIOCHEM, Bucharest, Romania, 30th October-1st November 2019.
}

Published: 15 October 2019

Keywords: stones; sulphates; Corvins' Castle; protection of cultural heritage

Stone monuments represent a big part of the world's cultural heritage. The deterioration of stone monuments is caused by a wide range of factors. Depending on the source of ions, various salts can be contained in building or decorative stones [1]. The most common salts are chlorides, nitrates, and sulphates. The possible sulphate sources include groundwater, seawater, and atmospheric pollution.

In this paper, we determined the sulphate content from model stones made of plaster mortar and mortar for construction and from stones from Corvins' Castle. The model stones were first dried at room temperature and at 100, 200, 300, and 400 degrees Celsius, respectively. In the first stage, the extraction of water-soluble substances was carried out. A quantity of $2 \mathrm{~g}$ of sample was added over $200 \mathrm{~mL}$ distilled water and then stirred at room temperature for $1 \mathrm{~h}$. The solution was further filtered and the sulphates obtained from the aqueous extract were determined using hydrochloric acid and barium chloride. A barium sulphate precipitate was obtained, which was further calcinated at 800 degrees Celsius for $1 \mathrm{~h}$. Finally, the amount of sulphates present in the sample was calculated.

The content of sulphates was determined from model stones (dried at different temperatures) and from the samples from Corvins' Castle. It can be seen that the model stones dried at 200 degrees Celsius had the largest amount of sulphates. The lowest content of sulphates was in the model stones dried at 100 degrees (Figure 1). Regarding the samples from the Corvins' Castle, the New Gate tower had an insignificant amount of sulphates, while the Deserted tower had the largest amount of sulphates (Figure 2). This could be due to the fact that in history, some restorers and conservators used noncompatible materials (e.g., cement), which are responsible for the generated sulphates.

A large quantity of sulphates was found in the samples from Corvins' Castle compared to the model stones. The presence of sulphate anions may be linked to the presence of the cement used in restoration. 


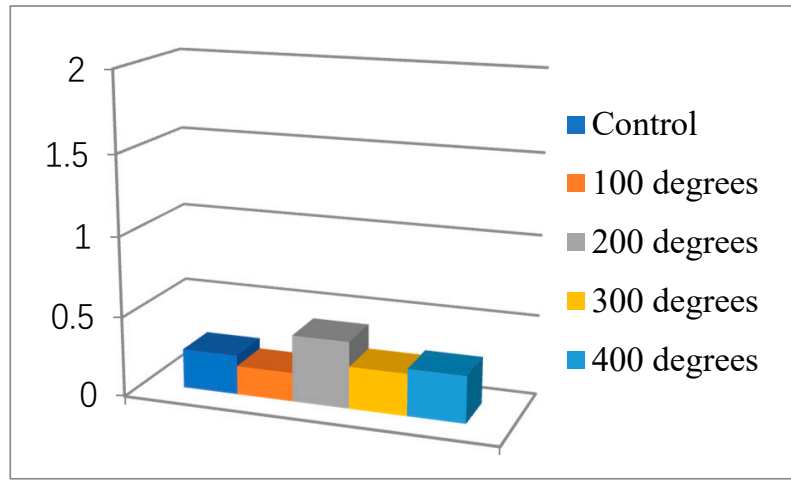

Figure 1. Percentage of sulphates in model stones.

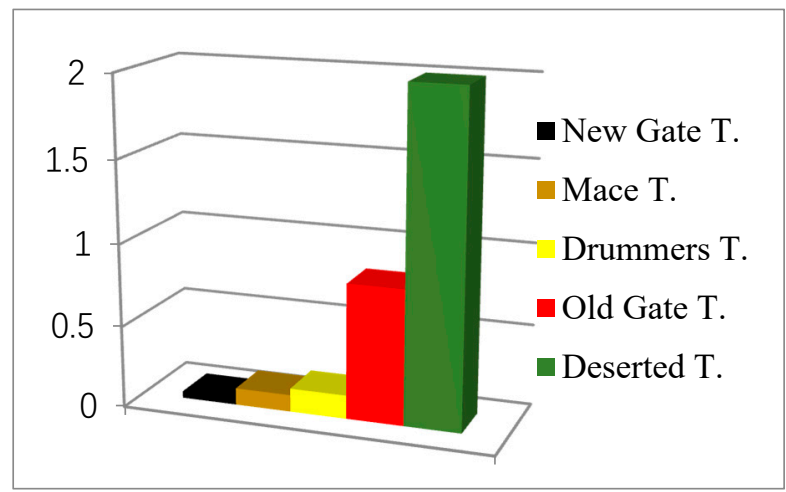

Figure 2. Percentage of sulphates in samples from Corvins' Castle.

Acknowledgments: This work was supported by a grant of the Romanian Ministery of Research and Innovation, CCCDI-UEFISCDI, project number PN-III-P1-1.2-PCCDI-2017-0476/51PCCDI/2018, within PNCDI III, PN.19.23.03.01.04 and 5PS/2019.

\section{Reference}

1. Hongguang, M.; Sui, L.; Xing, F.; Tian, H.; Zhou, Y. An effective transport model of sulfate attack in concrete. Constr. Build. Mater. 2019, 216, 365-378.

(C) 2019 by the authors. Licensee MDPI, Basel, Switzerland. This article is an open access article distributed under the terms and conditions of the Creative Commons Attribution (CC BY) license (http://creativecommons.org/licenses/by/4.0/). 